\title{
Sustainability indicators in Agriculture: A Review and Bibliometric analysis using Scopus database
}

\author{
ASMA ALI ${ }^{1 *}$, SIMONE PERNA ${ }^{2}$ \\ ${ }^{1}$ Environment and Sustainable Development Program, College of Science, University of Bahrain, \\ P.O. Box 32038, Bahrain \\ ${ }^{2}$ Department of Biology, College of Science, University of Bahrain, P.O. Box 32038, Bahrain \\ *Correspondence details: asmaali24@gmail.com
}

Submitted on: 2021, 17 June ; accepted on 2021, 17 July. Section: Research Papers

\begin{abstract}
Indicators are being used in many agricultural sustainability assessment methods, but disputes about a common indicator for the definition of sustainability have resulted in so many various indicators and methods of measurement. The objective of this review is to provide a bibliometric analysis of sustainability pillars and indicators that are significantly prevalent. In addition, this paper evaluates the impact of pillars and indicators on scientific research through the analysis of their citation and trend. Using Scopus database, a total of 30 articles related to crops farming have been selected and more than 500 indicators were analyzed. This study only looked at the top 3 indicators of each pillar which were discussed in at least 7 articles and can be used to measure farm sustainability in different crop production fields: (soil erosion, crop diversity and pesticides) for the environmental pillar, (education and training) for the social pillar, and (profitability, productivity and farm income) for the economic pillar. Results also showed that the environmental pillar is the most tackled and cited with a mean citation of about 60 . Pesticides on the other hand is found to be the oldest indicator in terms of its average year of publication. It was the most cited indicator in 2005 of more than 250 citations. The least cited indicators are farm income and training with less than 10 mean citations. In addition, the economic pillar is considered one of the recently discussed and widely implemented with a total of 7 published articles in 2020. The obtained results may be viewed as a set of indicators that can be considered in future policies to detect significant challenges, and improve agricultural sustainability strategies.
\end{abstract}

Keywords: Sustainability, indicators, assessment, farm-level

\section{Introduction}

The world's population is expected to grow by two billion people over the next 30 years (UN, 2019), posing the challenge of producing enough food for humanity (Arnés et al., 2018). Extensive food production associated with the substantial use of fertilizers, pesticides and water has caused a considerable environmental impact (Pretty et al., 2011). These impacts generated from the process of agricultural production have piqued the interest of researchers in the field of sustainability. A large and growing body of literature has investigated the definition of sustainability and identified a variety of sustainability explanations (Curran et al., 2020; Cruz et al., 2018; Halberg, 2012; Wirén-Lehr, 2001). Recent attention focused on the provision of the World Commission on Environment and 
Development-WCED (the Brundtland Commission): "Humanity has the ability to make development sustainable, to ensure that it meets the needs of the present generation without compromising the ability of future generations to meet their own needs". The WCED description of the term has remained durable, considering the numerous numbers of publications on sustainable development that followed the Brundtland report, in which several attempts were made to express sustainability in a concept that fits theoretical and operational purposes (World Bank, 2008; Cruz et al., 2018; Latruffe et al., 2016; Meul et al., 2008; Roy \& Chan, 2012). Since then, sustainability principles have been and are experiencing rapid change and modifications in perspective. The three sustainability pillars highlighted at the 2002 World Summit on Sustainable Development (social, environmental and economic) concluded the explanation of this concept (Pham \& Smith, 2014; Frantzius, 2004) and are now the leading drivers that determine the planning for growth. Since then, literatures on agricultural development complies with sustainability. The implementation and evaluation of sustainable agriculture has become a principal challenge for agricultural research, practice and policy (Santiago-Brown et al., 2015). Fallah-Alipour et al., (2018) described sustainable agricultural systems as the conservation of the environment, the implementation of effective methods for agricultural production and the improvement of human health over time. The assessment of agricultural sustainability is a critical tool for fostering the idea of sustainable agricultural systems, as it incorporates the principles of sustainability into agricultural policy preparation and decision-making (Talukder \& Blay-Palmer, 2017).

Indicators are used in measuring sustainability, and are applied in many methods of evaluation (Baelemans \& Muys, 1998). The design of indicators for assessing agricultural sustainability has been dealt with by several authors. Despite decades of research, this continues to be debated among researchers. Reed et al., (2006) have found that sustainability assessments through indicators must be systemic. A series of sustainability assessment approaches have been developed (Riley, 2001; Santiago-Brown et al., 2015), and there seems to be an "indicator explosion" during the last few decades (Riley, 2001). An appropriate measure of a system cannot be given by the collection of several separate indicators. Having so many indicators often cause a host of difficulties, such as data acquisition, validation, etc. In addition, results are often not adequately taken into consideration when concentrating only on a single indicator (Bartzas \& Komnitsas, 2020). Although the same indicators can be used for these approaches, their mechanism and area of operation are rather different (Bhushan \& Rai, 2004). The creation of an acceptable set of indicators was noted to be an important and complex issue as indicators can offer an insight concerning sustainability. The selection of "essential" indicators is difficult to come up with (Bossel, 2002). However, an accurate way of selecting indicators is needed, as discussed by (OECD, 2001). Several researchers such as Binder et al., (2009) \& Bélanger et al., (2012) have suggested criteria that should be fulfilled by a strong indicator, without offering realistic selection process guidance. Modeling technologies, though, help to investigate resilience or create alternate scenarios to forecast environmental, social and economic vulnerabilities. A variety of evaluation tools, including Environmental Impact Assessment (EIA), Sustainability Standards with Principles, Criteria and Indicators (PC\&I), Life Cycle Assessment (LCA) and CostBenefit Analysis (CBA) have been proposed over the years for the sustainability assessment of production systems. Many of these evaluations, though, rely primarily on the components of environmental sustainability (van der Werf \& Petit, 2002) and a very little, however, concentrate on evaluating the three pillars of sustainability (environmental, economic and social) for individual farms level (Farrell \& Hart, 1998; Bhushan \& Rai, 2004). Up to now, an increasing number of sustainability systems, indicator-based evaluation methodologies for the assessment of agricultural sustainability 
have been developed. In most cases, however, the use of current and well-established sustainability measurement approaches and tools such as Multi-Criteria Decision Analysis (MCDA), Sustainability Assessment of Food and Agriculture Systems (SAFA), the IDEA method (Indicateurs de Durabilité des Exploitations Agricoles), Monitoring Tool for Integrated Farm Sustainability (MOTIFS), a component- based framework for the European Union (SAEMETH) and the Response-Inducing Sustainability Evaluation model (RISE) necessitates a wide range of indicators, which increases the time required for data collection, planning, and analysis (Dantsis et al., 2010; Zulfiqar \& Thapa, 2017). All methodologies have some distinctive features. RISE is found to be the most effective tool, but when it comes to scientific related issues, MCDA is a better option (Talukder \& Blay-Palmer, 2017) .

Considering the vast number of sustainability evaluation studies for agricultural systems available in the literature, and the lack of a standardized set of indicators, it is well-intentioned to know the common indicators that have been used and applied widely. To fill the gap, this study will identify potential eligible articles and answer the following questions: what are the significant indicators in the scientific discovery that are most prevalent? what are the most commonly cited pillars and indicators? and what is the yearround trend for each pillar and indicator? To answer our research questions, a review and bibliometric analysis of the indicators listed in various research papers were conducted in order to (1) provide a descriptive overview of the top three indicators that have been widely applied and considered for crop farms level assessment, and (2) evaluate the impact of these indicators on the scientific field through citation and trend analysis. The greater an article's citation, the higher is the dissemination and the influence of such indicator on scientific research.

\section{Materials and Methods}

A narrative review and bibliometric analysis were carried out to analyse, in terms of interpretation and application, the impact of major indicators on the field of farm sustainability. This analysis requires qualitative and quantitative data such as sustainability indicators, citations count and trend. The search was done to explore all published articles from 1993 to October 2020 that are related to the assessment of sustainability by the application or contemplation of various pillars and indicators in the field of crops production. Scopus search engine database was chosen in order to select the relevant papers. Initially, when looking for articles published in Scopus, keywords and Boolean operators (AND/OR) were used to create a logical relationship between the terms. The search approach was based on the following keyword phrases: (AGRICULTURAL) AND (INDICATOR) AND (FARM LEVEL). The methodology was performed in two parts: (1) extract all indicators listed in the selected articles and grouped them within the sustainability pillars, (2) measure the number of citations for each article to understand the degree of spread and impact of each pillar and indicator. The derived indicators were classified by sustainability pillar as this is considered to be more sensible.

\section{Statistical analysis}

Statistical analyses were performed using SPSS 25.0 (SPSS, Inc., Chicago, IL, USA) and JAMOVI program on $\mathrm{R}$ script. Data have been reported as mean and standard deviation (SD), frequencies and \% based on the total investigated sample, in addition for all variables were given as descriptive statistics. Continuous variables were calculated between groups by means and SDs, including the endpoints. The analysis of covariance (ANCOVA) as a covariate (articles and year of publication) was used to compare the 
"adjusted mean" of different indicators. The general linear model (GLM) univariate analysis of covariance procedure provides regression analysis and analysis of variance for one dependent variable by one or more factors and/or variables. Using this GLM procedure, it is possible to test null hypotheses about the effects of other variables (year of publication and articles) on the means of a single dependent variable (citations). The effects for each pillar and indicator across time were separately analyzed using ANCOVA univariate analysis. The level of statistical significance was set at $\mathrm{p}<0.05$.

\section{Results}

\section{The portfolio selection}

The initial screening showed a total of 1,088 papers. The search was then limited to the following subject areas: (1) Environmental Science, and (2) Agriculture Science/Agronomy. The exact keyword "Sustainability" was applied to obtain more accurate results. 128 papers were shortlisted after such refinement. Finally, this search was limited to only "articles", "English language" and "open access" and number of papers were reduced considerably to 37 . All studies were thoroughly reviewed for their eligibility. 21 articles were excluded as they mainly fall inside animals, poultry, live stocks or fisheries. In addition, 14 relevant papers were included to the search results, ending up with a sum of 30 articles to be analyzed in this study. The search strategy was carried out and the search history was saved using the 'Save' feature on the Scopus website.

\section{Portfolio analysis}

The search yielded 30 articles, 6 of them have only considered environmental indicators $(20 \%), 1$ article focused mainly on economic indicators (3\%), and the rest 23 articles considered indicators for the three pillars of sustainability (77\%). Table 1 lists the 30 articles, their year of publication and number of citations. The oldest year was 1993, followed by 1994, 2001 through 2020. When evaluating number of publications per year, it is found that from 1993 to 2011, the number was constant with no more than 1 article per year. Then it slightly increased from 2 to 4 publications per year between 2015 to 2019 and concluded with a large spike in the field of applications in 2020 with 9 articles.

\section{Identification of common indicators}

The common indicators refer to the most repeated indicators within the identified articles. From the 30 articles analyzed, a list of 538 indicators were identified (253 environmental, 146 social and 139 economic). Common indicators were counted to determine the top three indicators that were repeated 7 times and more. The results revealed a total of 8 key indicators presented in the descriptive analysis in Table. 2. 
Table 1 -List of the 30 articles, year, citations and number of articles per year

\begin{tabular}{lcc}
\hline REFERENCED ARTICLE & YEAR & NUMBER OF CITATIONS \\
\hline (Taylor et al., 1993) & 1993 & 55 \\
(Stockle et al., 1994) & 1994 & 51 \\
(Rigby et al., 2001) & 2001 & 220 \\
(Dantsis et al., 2010) & 2010 & 82 \\
(Pacini et al., 2011) & 2011 & 11 \\
(Gutzler et al., 2015) & 2015 & 70 \\
(Sánchez et al., 2015) & 2015 & 11 \\
(Ruiz-Martinez et al., 2015) & 2015 & 19 \\
(Santiago-Brown et al., 2015) & 2015 & 23 \\
(M. de Olde et al., 2016) & 2016 & 13 \\
(Li et al., 2016) & 2016 & 10 \\
(Gaviglio et al., 2017) & 2017 & 15 \\
(Zulfiqar \& Thapa, 2017) & 2017 & 16 \\
(Nchanji et al., 2017) & 2017 & 5 \\
(Berbeć et al., 2018) & 2018 & 11 \\
(Fallah-Alipour et al., 2018b) & 2018 & 2 \\
(Sulewski et al., 2018) & 2018 & 17 \\
(Mili \& Martínez-Vega, 2019) & 2019 & 9 \\
(Veveris et al., 2019) & 2019 & 2 \\
(Soldi et al., 2019) & 2019 & 3 \\
(Triviño-Tarradas et al., 2019) & 2019 & 3 \\
(Bartzas \& Komnitsas, 2020) & 2020 & 4 \\
(Tzouramani et al., 2020) & 2020 & 2 \\
(Gómez-Limón et al., 2020) & 2020 & 1 \\
(Abdul Rahman et al., 2020) & 2020 & 0 \\
(Triviño-Tarradas et al., 2020) & 2020 & 0 \\
(Uthes et al., 2020) & 2020 & 2 \\
(Gambart et al., 2020) & 2020 & 2020 \\
(Stylianou et al., 2020) & 2020 & \\
(Curran et al., 2020) & & \\
\hline
\end{tabular}

Table 2-Percentage and number of articles based on each indicator

\begin{tabular}{llll}
\hline SUSTAINIBILITY PILLARS & INDICATORS & $\%$ & $(\mathrm{~N})$ \\
\hline Economic & Productivity & 36.7 & 11 \\
& Farm Income & 26.7 & 8 \\
& Profitability & 23.3 & 7 \\
\hline Social & Education & 26.7 & 8 \\
& Training & 26.7 & 8 \\
\hline Environmental & Soil erosion & 40.0 & 12 \\
& Pesticides & 36.7 & 11 \\
& Crop diversity & 33.3 & 10 \\
\hline
\end{tabular}


It is apparent from this table that environmental pillar is the most tackled in terms of total number of articles, and soil erosion is the most focused and discussed indicator by researches among all $(\mathrm{n}=12,40 \%)$. Productivity as economic indicator and pesticides as environmental indicator were addressed equally $(\mathrm{n}=11,36.7 \%)$. In comparison, the social indicators "education and training" were given equal consideration by researchers, as both are equivalent $(n=8,26.7 \%)$. Farm income received less attention after it was introduced in recent articles published in 2017.

\section{Citations and trend}

\section{Comparison between sustainability pillars}

After identifying the common indicators, the number of citations was evaluated in attempt to elucidate the effect of such indicators on the scientific research field. Figure 1 represents the estimated marginal mean citations for the articles being analyzed with the observed citation scores. Dots in the graph represent the spreading and outlier of the citation data.

The most cited pillar is the environment, which was tackled in 22 articles since 1993 with an average citation of about 60 . The economic and social pillar citations are nearly equal, with an average of 25 . The environmental pillar was addressed in one article, which has the highest citation score of more than 200. The citations of economic pillar range from 10 to 50 , and for the social pillar from 5 to 80 .

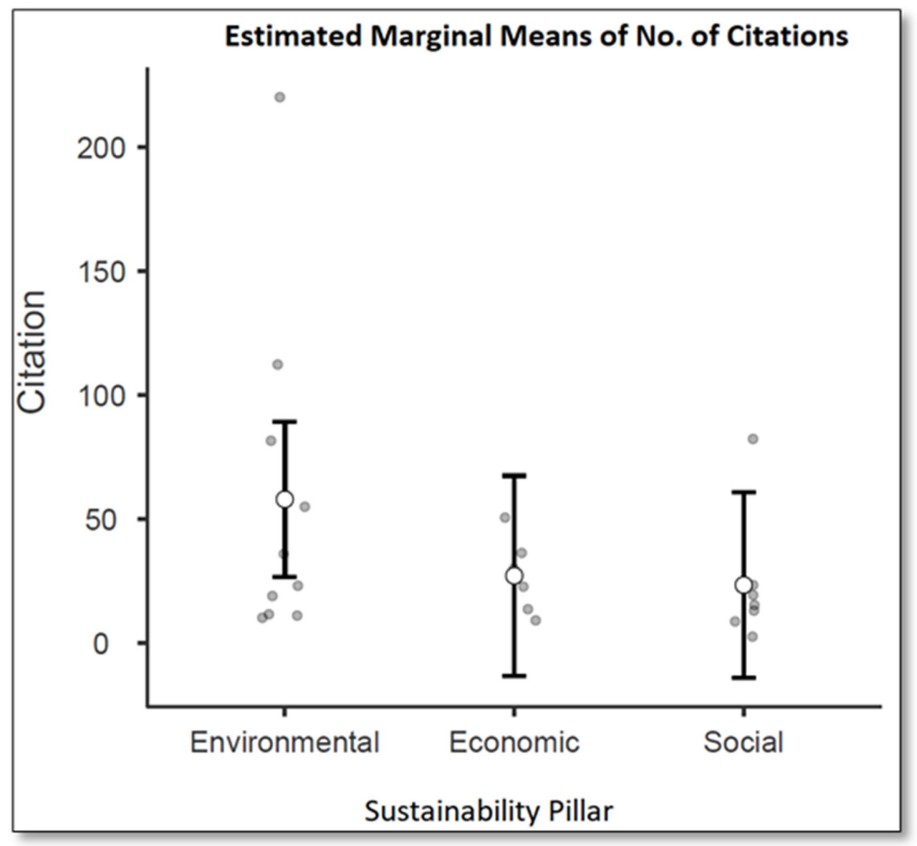

Figure 1 - Estimated marginal mean citations by pillar

Figure 2 reflects the pattern of each pillar over the years. The Environmental pillar was the oldest with a constant trend between 1993 and 2011. Then a fluctuation of interest was observed between 2015 and 2019. In 2020, researchers devoted considerable attention to the environmental pillar, during which a drastic increase was detected reaching up to 6 articles.

From 2015 until now, the economic pillar has gained wide attention from researchers. Nowadays, this pillar is considered one of the most discussed and widely implemented with a total of 7 published articles in 2020 . 
There were no articles considering the social pillar noted between 1993 and 2001, which leaves a massive gap in this field. Followed that, just 1 article took into account social indicators in the years 2010, 2015, 2016 and 2017. Recently, this pillar had enormous influence on the field with a total of 6 published articles in 2020.

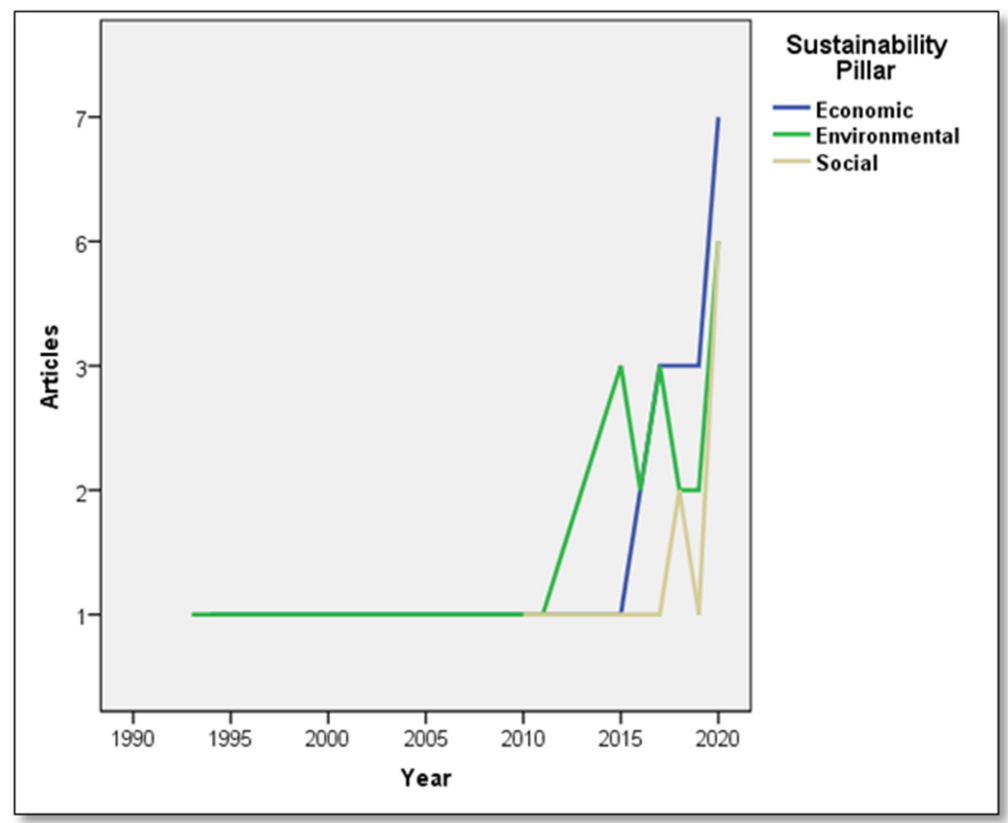

Figure 2 - The pattern of each pillar over the years

\section{Comparison between sustainability indicators}

A box plot approach was used to give an overview regarding the up-to-date indicators by representing their average year of publication (Figure 3 ). Starting with the environmental pillar, pesticides is the oldest indicator in terms of its average year of publication in 2011, followed by soil erosion with an average publication year in 2016. Researchers started to use these indicators since 1993. Soil erosion was then ignored for almost 17 years before it was back again in 2011. Pesticides was discussed in majority of articles published between 2001 and 2020. On the other hand, crop diversity caught the attention in 2011. Then, between 2016 and 2019, it was listed in several journals, with great recent interest in 2020. The average year of publication for crop diversity is 2018 .

Moving on to economic pillar, farm income is the most recent indicator. All articles were published between 2018 and 2020, with 2019 as average year. Moreover, profitability was mostly tackled between 2005 and 2020, with only one article published in 1994. In average, the year of publication for profitability indicator is in 2017. Productivity was mentioned in all articles with 2018 as average year of publication.

Finally, considering the social pillar, education was the oldest indicator since 2010, with an average year in 2016. Training, on the other hand, which was tackled in articles published in 2015, has an average year of 2017. Both indicators were found together in almost all articles being analyzed. 


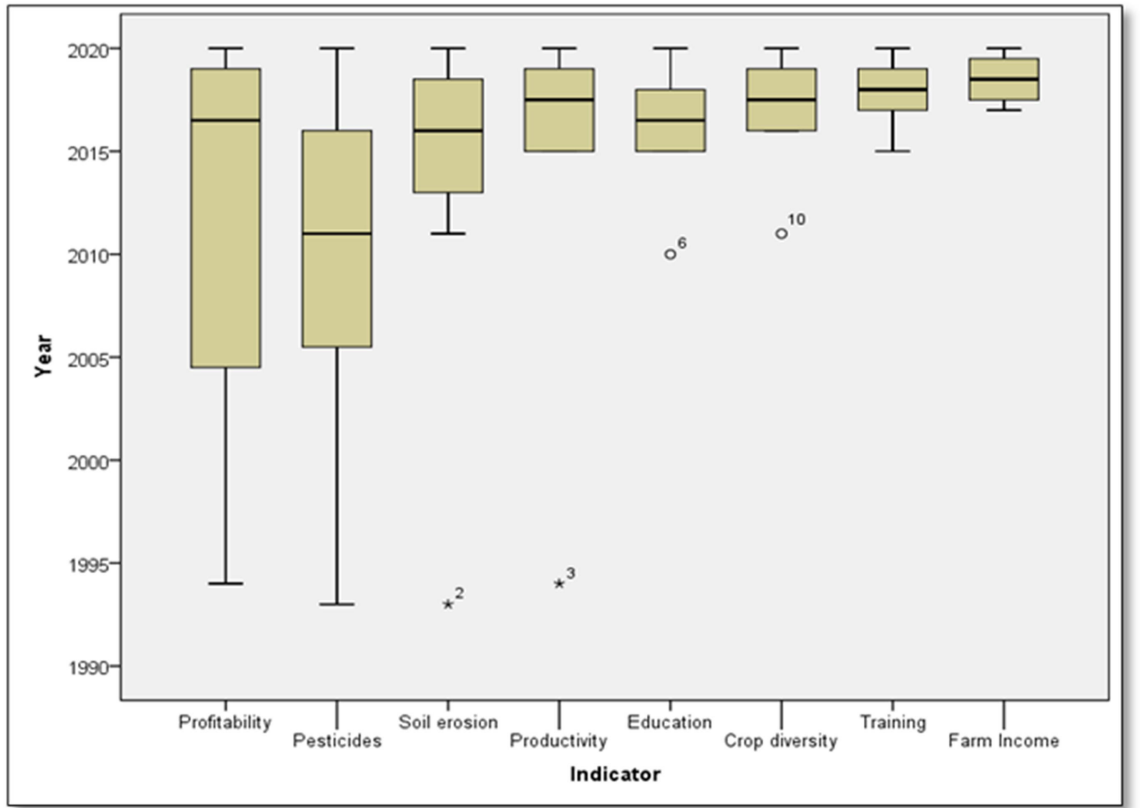

Figure 3 - Box plot representing the mean of each indicator by year of publication

The citation of each indicator over time is represented in Figure 4. Mostly, all indicators had a fluctuating citation trend. It can be seen from the graph below that the concentration of all indicators were between the years 2017 and 2020. The most recent indicator is farm income and the oldest one is pesticides in terms of their year of publication. The most cited indicator is pesticides with more than 250 citations in 2005 , followed by soil erosion and education with citations between 150 and 210 . The least cited indicators are farm income and training with less than 50 citations.

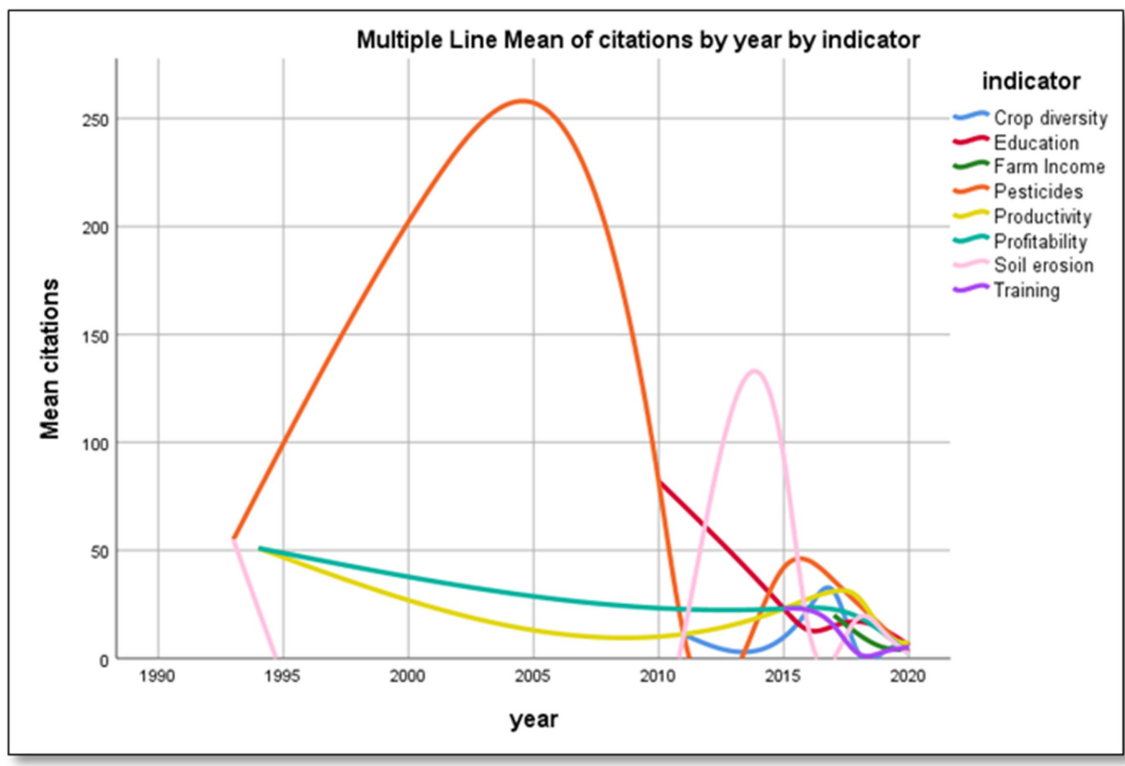

Figure 4 - Number of citations per indicator overtime

Overall, the mean citation for each indicator is presented in Figure 5. Pesticides has the highest mean citation of about 42 , followed by productivity with a mean citation of 28 and profitability with a mean citation of 20 . Training and farm 
income have the least mean citation of about 4 and 7, respectively. Soil erosion was presented in many articles, but the mean citation is only 13 which is considered very low compared to other indicators.

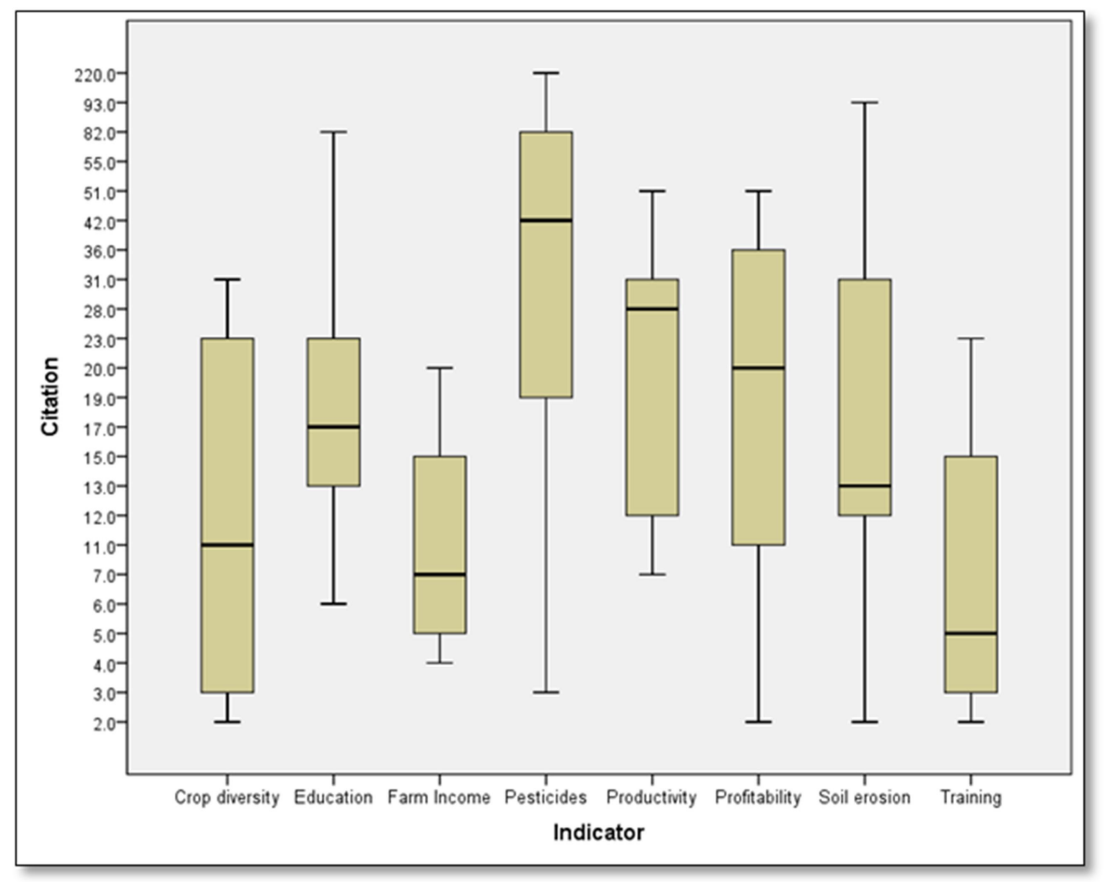

Figure 5 - Mean citations per indicator

\section{Discussion}

This study showed that: (1) the key indicators for sustainability in agriculture are: pesticides, crop diversity, soil erosion, productivity, farm income, profitability, education and training; (2) Environmental pillar is the most tackled in terms of number of articles and the most cited; (3) Pesticide is the oldest and most cited indicator; (4) farm income is the most recent and less cited indicator; (5) the economic pillar recently has gained wide attention from researchers.

The increased attention by researchers on agricultural sustainability indicators is due to the announcement of Sustainable Development Goals (SDGs) by the United Nations General Assembly in 2015. In this respect, many studies have been published after this year and several indicators have been defined, but yet, there are still disputes on the concept of a coherent set of indicators.

\section{Environmental indicators}

Knowing the significance of this pillar, which is found to be the oldest, , it is not surprising that it results the most tackled and most cited. Our results showed that environmental indicators have the most popularity among all. This finding leads us to confirm the study of Latruffe et al., (2016), who discovered that environmental pillar has undergone an 'indicator boom' due to the importance paid by scientists to this pillar. Pesticides is found to be the oldest and most cited indicator. The use of pesticides has grown significantly and been used as an indicator by many researches. Owing to the heavy use of pesticides, the current farming practices used by many indigenous farmers have been viewed as unsustainable (Cruz et al., 2018). This prompted researchers long ago to give 
enormous attention to this indicator. In addition, Liu et al., (2013) stated that the high use of pesticides has contributed to the depletion of ecological diversity and reducing environmental sustainability. In addition, Nchanji et al., (2017) suggested new ways to reduce the danger of pesticides on the environment through the use of biological pesticides such as neem leaves to combat pests in the cultivation of vegetables and crops.

Soil erosion is the most discussed indicator which was presented in 12 articles. The importance given to this indicator is due to its shared issue between farms (Tsymbarovich et al., 2020). Soil erosion is the actual removal of soil from an environment by either wind or water. It causes severe impact such as land degradation and therefore affect agricultural production. Our finding of this indicator as the most common supports the study of Gambart et al., (2020), who intended to enhance farm sustainability by minimizing the risk of soil erosion.

In addition, the inquiries made by Hayati, (2017) into the most popular approaches in the field studying environmental pillar suggested using soil erosion as an important indicator for measuring farm sustainability.

Crop diversity is known as the number of different crops grown on each farm. It raises field productivity and lowers agricultural income uncertainty (Gutzler et al., 2015). Our results confirm the study of Dantsis et al., (2010) who found that crop diversity have been identified as an indicator with positive impact on agricultural sustainability. An interesting significant connection is found between the two common indicators "crop diversity and soil erosion". It was reported by Roy \& Chan, (2012) that some crops (e.g. corn) are more sensitive to soil erosion than others (e.g. Cereals), so the distribution of crops can influence the risk of soil erosion. In addition, Ervidová, (2002) stated that the distribution of crops can affect the risk of soil erosion. It can be said that if crop diversity is not properly planned, it could adversely affect soil erosion.

\section{Economic indicators}

Even though much of the attention in the sustainability debate is really on the environmental pillar, farms still need to be economically competitive in order to be sustainable in the long run. The economic pillar has recently gained wide attention from researchers. A possible explanation as mentioned by Barnes \& Thomson (2014) is that experts are recently putting their effort to monitor the progress of "sustainable intensification" in agricultural production which has become a priority concern for policy makers and international organizations. Farm accounting investigation is an approach to measure their economic viability. Such approach was conducted by many researchers to examine the financial changes in farms (Buckley et al., 2015; Mili \& Martínez-Vega, 2019).

Productivity is the most tackled economic indicator which was mentioned in all articles, because the effective use of production factors is a fundamental principle of the sustainable economic growth of any region. This emphasizes the results if many studies by Ryan et al., (2016) \& M. de Olde et al., (2016) who stressed on the positive correlation between economic performance and sustainability, powered by higher production and more efficient input usage.

Profitability was mostly tackled between the years 2005 and 2020. In order to be able to take reasonable management decisions it is now important to incorporate conceptions of profitability (Ouiminga, 2018). Profitability is an important indicator because a farm will not be sustainable if it is not profitable. 
This indicator has been widely applied by international organizations such as the European Commission who introduced profitability as one of the indicators in the European appraisal frameworks (Stylianou et al., 2020). Farm income, on the other hand, is used to measure farm performance. It has been reported that many small farms frequently rely on European Union subsidies to survive (Hanrahan et al., 2018). The income generated by farmers performance is an important element for income security independent.

Significantly, these three indicators (productivity, profitability and farm income) are widely used in different assessment tools such as Monitoring Tool for Integrated Farm Sustainability (MOTIFS), Sustainability Assessment of Food and Agriculture systems (SAFA) and Response-Inducing Sustainability Evaluation (RISE). It must be mentioned that economic viability is often a prerequisite for several aspects of the social pillar (Sauvenier et al., 2005).

\section{Social Indicators}

Social indicators are used to assess the potential and willingness of farmers to handle various situations (Gaviglio et al., 2017; Santiago-Brown et al., 2015; Stylianou et al., 2020). It is shown that education and training were given equal consideration by researcher in terms of number of articles, even though education is the oldest in terms of researcher's interest while training is the least cited. Education and training are difficult indicators to quantify, since they are subjective and are mostly qualitative (Volkov et al., 2019). These indicators were previously focused by many articles, for example Latruffe et al. (2016) and Ntshangase et al. (2018) who considered both "education \& training" as the key indicators for social pillar. A study by Sabiha et al. (2016) claimed that education is one of farmers' significant perceptions of the opportunity to enforce the principles of sustainable development. Our results are in line with this study who also reported that farmer's training is an important indicator under the quality-oflife theme. Furthermore, to ensure sustainable performance at farms, it is critical to identify training needs when introducing any new activities in the farm management.

\section{Limitation of this study}

This study is the first research using the Scopus database to perform a comprehensive bibliometric analysis and review of the chosen indicators. Challenges were experienced in terms of indicators recording. Few of them have been rephrased in order to quickly detect the common indicators. For instance, the "educational level" and "level of education" both share the same concept within the social pillar, but have been interpreted differently. This indicator has been recorded as "education". Another constraint was to take into account only the top 3 indicators of each pillar, that were reflected in seven or more articles. This restricts the study and can lead to not consider other significant indicators.

\section{Conclusions}

One of the most pressing needs of the agricultural sector around the world is the availability of reliable and accurate indicators. Many stakeholders in the agricultural sector, such as farmers and policymakers, are increasingly concerned about the efficiency of various farming systems and are looking for reliable indicators of sustainability improvements. This requirement stems from the fact 
that there are many indicators in the field that have been used to monitor farm sustainability. For this reason, a bibliometric analysis was conducted to better comprehend the various indicators and to assess the impact of these indicators as well as the sustainability pillars on the scientific field. According to the findings, environmental pillar is the most addressed and cited. Whereas, the economic pillar is regarded as one of the most recently debated. In addition, pesticide is found to be the oldest indicator, while farm income and training both received the least attention. Moreover, the study findings provide useful insight into the most important and relevant indicators that emerge as a result of the analysis and these are: pesticides, crop diversity, soil erosion, productivity, farm income, profitability, education and training. Those eight indicators have been shown to be related directly to crop farming sustainability. The obtained results may be viewed as a set of indicators that can be considered in future policies or assessment tools in order to detect significant challenges, and improve agricultural sustainability strategies.

A decision about whether to treat each indicator equally important or to prioritize certain indicators based on different weights should be considered. At this point in the study, we have not focused on developing farm-level sustainability measurement tools, and despite the debate about their utility, the advantage of our findings is the limited number of indicators applied per farm that can further simplify the data, making it easier to spot trends over the time. This makes it much easier to comprehend changes in sustainability as a result of proper policy development. Some assessment tools covered almost all of those eight indicators such as RISE and SAFA. However, Multi-Criteria Decision Analysis (MCDA) methodologies are becoming increasingly prevalent in agricultural decision-making. The MCDA methodology is a useful tool for future work to develop goals and weight the criteria and then apply those eight indicators to field experiments.

\section{References}

Abdul Rahman N., Larbi A., Kotu B., Kizito F., and Hoeschle-Zeledon I., 2020. Evaluating Sustainable Intensification of Groundnut Production in Northern Ghana Using the Sustainable Intensification Assessment Framework Approach. Sustainability, 12(15). Retrieved from https://doi.org/10.3390/SU12155970

Arnés E., Díaz-Ambrona C.G.H., Marín-González O., and Astier M., 2018. Farmer Field Schools (Ffss): A Tool Empowering Sustainability and Food Security in Peasant Farming Systems in the Nicaraguan Highlands. Sustainability (Switzerland), 10(9). Retrieved from https://doi.org/10.3390/Su10093020

Baelemans A., and Muys B., 1998. A Critical Evaluation of Environmental Assessment Tools for Sustainable Forest Management. Proceedings of the International conference on Life Cycle Assessment in agriculture, agro-industry and forestry, Brussels, 65-75.

Barnes A.P., and Thomson S.G., 2014. Measuring Progress Towards Sustainable Intensification: How Far Can Secondary Data Go? Ecological Indicators, 36, 213220. Retrieved from https://doi.org/10.1016/J.Ecolind.2013.07.001

Bartzas G., and Komnitsas K., 2020. An Integrated Multi-Criteria Analysis For Assessing Sustainability Of Agricultural Production At Regional Level. Information Processing In Agriculture, 7(2), 223-232.

Retrieved from https://doi.org/10.1016/J.Inpa.2019.09.005 
Bélanger V., Vanasse A., Parent D., Allard G., and Pellerin D., 2012. Development of Agri-Environmental Indicators To Assess Dairy Farm Sustainability in Quebec, Eastern Canada. Ecological Indicators, 23, 421-430. Retrieved from https://doi.org/10.1016/J.Ecolind.2012.04.027

Berbeć A.K., Feledyn-Szewczyk B., Thalmann C., Wyss R., Grenz J., Kopiński J., Stalenga J., and Radzikowski P., 2018. Assessing the Sustainability Performance of Organic And Low-Input Conventional Farms From Eastern Poland with the RISE Indicator System. Sustainability, 10(6). Retrieved from https://doi.org/10.3390/Su10061792

Bervidova, L. (2002). Labour productivity as a factor of sustainable economic development of the CR agriculture. Agricultural Economics, 48(2), 55-59.

Bhushan N., and Rai K., 2004. Strategic Decision Making. Applying the Analytic Hierarchy Process. Springer, London, 9, 11-21. Retrieved from http://www.springer.com/978-1-85233-756-8

Binder C.R., Feola G., and Steinberger J.K., 2009. Considering the Normative, Systemic and Procedural Dimensions in Indicator-Based Sustainability Assessments in Agriculture. Environmental Impact Assessment Review, 30(2), 71-81. Retrieved from https://doi.org/10.1016/J.Eiar.2009.06.002

Bossel H., 2002. Assessing Viability and Sustainability: A Systems-Based Approach for Deriving Comprehensive Indicator Sets. Journal of Chemical Information and Modeling, 53(12), 1689-1699.

Retrieved from https://Www.Jstor.Org/Stable/Pdf/26271829.Pdf?Refreqid= Excelsior\%3a20f663923348ceeb6cac0e995c1 f96e6

Buckley C., Wall D.P., Moran B., and Murphy P.N.C., 2015. Developing the EU Farm Accountancy Data Network to Derive Indicators Around the Sustainable Use of Nitrogen and Phosphorus at Farm Level. Nutrient Cycling In Agroecosystems, 102(3), 319-333. Retrieved from https://doi.org/10.1007/S10705-015-9702-9

Cruz J.F., Mena Y., and Rodríguez-Estévez V., 2018. Methodologies for Assessing Sustainability in Farming Systems. Sustainability Assessment and Reporting. Retrieved from https://doi.org/10.5772/Intechopen.79220

Curran M., Lazzarini G., Baumgart L., Gabel V., Blockeel J., Epple R., Stolze M., and Schader C., 2020. Representative Farm-Based Sustainability Assessment of the Organic Sector in Switzerland Using the SMART-Farm Tool. Frontiers In Sustainable Food Systems, 4.

Retrieved from https://doi.org/10.3389/Fsufs.2020.554362

Dantsis T., Douma C., Giourga C., Loumou A., and Polychronaki E.A., 2010. A Methodological Approach to Assess and Compare the Sustainability Level of Agricultural Plant Production Systems. Ecological Indicators, 10(2), 256-263. Retrieved from https://doi.org/10.1016/J.Ecolind.2009.05.007

Ervidová L.B., 2002. Labour Productivity as a Factor of Sustainable Economic Development of the CR Agriculture. 2002(2), 55-59.

Fallah-Alipour, S., Mehrabi Boshrabadi, H., Zare Mehrjerdi, M. R., \& Hayati, D. (2018). A framework for empirical assessment of agricultural sustainability: The case of Iran. Sustainability, 10(12), 4823.

Retrieved from https://doi.org/10.3390/Su10124823

Farrell, A., \& Hart, M. (1998). What does sustainability really mean?: The search for useful indicators. Environment: science and policy for sustainable development, 40(9), 4-31. Retrieved from https://doi.org/10.1080/00139159809605096

Gambart C., Swennen R., Blomme G., Groot J.C.J., Remans R., and Ocimati W., 2020. Impact and Opportunities of Agroecological Intensification Strategies on Farm Performance: A Case Study of Banana-Based Systems In Central And South- 
Western Uganda. Frontiers in Sustainable Food Systems, 4 (87), 1-13. Retrieved from https://doi.oOrg/10.3389/Fsufs.2020.00087

Gaviglio A., Bertocchi M., and Demartini E., 2017. A Tool for the Sustainability Assessment of Farms: Selection, Adaptation and Use of Indicators for an Italian Case Study. Resources, 6(4), 60.

Retrieved from https://doi.org/10.3390/Resources6040060

Gómez-Limón J.A., Arriaza M., and Guerrero-Baena M.D., 2020. Building a Composite Indicator to Measure Environmental Sustainability Using Alternative Weighting Methods. Sustainability, 12(11).

Retrieved from https://Doi.Org/10.3390/Su12114398

Gutzler C., Helming K., Balla D., Dannowski R., Deumlich D., Glemnitz M., Knierim A., Mirschel W., Nendel C., Paul C., Sieber S., Stachow U., Starick A., Wieland R., Wurbs A., and Zander P., 2015. Agricultural Land Use Changes - A ScenarioBased Sustainability Impact Assessment For Brandenburg, Germany. Ecological Indicators, 48, 505-517.

Retrieved from https://Doi.Org/10.1016/J.Ecolind.2014.09.004

Halberg N., 2012. Assessment Of The Environmental Sustainability Of Organic Farming: Definitions, Indicators And The Major Challenges. Canadian Journal Of Plant Science, 92(6), 981-996. Retrieved from https://Doi.Org/10.4141/CJPS2012-035

Hanrahan L., Mchugh N., Hennessy T., Moran B., Kearney R., Wallace M., and Shalloo L., 2018. Factors Associated With Profitability In Pasture-Based Systems Of Milk Production. Journal Of Dairy Science, 101(6), 5474-5485. Retrieved from https://Doi.Org/10.3168/Jds.2017-13223

Hayati D., 2017. A Literature Review on Frameworks and Methods for Measuring and Monitoring Sustainable Agriculture. Technical Report.

Latruffe L., Diazabakana A., Bockstaller C., Desjeux Y., Finn J., Kelly E., Ryan M., and Uthes S., 2016. Measurement of Sustainability in Agriculture: A Review of Indicators. Studies in Agricultural Economics, 118(3), 123-130. Retrieved from https://doi.org/10.7896/J.1624

Li Q., Amjath-Babu T.S., Zander P., Liu Z., and Müller K., 2016. Sustainability of Smallholder Agriculture in Semi-Arid Areas Under Land Set-Aside Programs: A Case Study From China's Loess Plateau. Sustainability, 8(4), 1-17. Retrieved from https://doi.org/10.3390/Su8040395

Liu Y., Duan M., and Yu Z., 2013. Agricultural Landscapes snd Biodiversity in China. Agriculture, Ecosystems and Environment, 166, 46-54. Retrieved from https://doi.org/10.1016/J.Agee.2011.05.009

M. De Olde E., Oudshoorn F.W., Bokkers E.A.M., Stubsgaard A., Sørensen C.A.G., and De Boer I.J.M., 2016. Assessing the Sustainability Performance of Organic Farms in Denmark. Sustainability, 8(9).

Retrieved from https://doi.org/10.3390/Su8090957

Meul M., Passel S. Van, Nevens F., Dessein J., Rogge E., Mulier A., and Hauwermeiren, A. Van., 2008. MOTIFS: A Monitoring Tool for Integrated Farm Sustainability. Agronomy for Sustainable Development, 28(2), 321-332. Retrieved from https://doi.org/10.1051/Agro:2008001

Mili S., and Martínez-Vega J., 2019. Accounting For Regional Heterogeneity of Agricultural Sustainability in Spain. Sustainability, 11(2). Retrieved from https://doi.org/10.3390/Su11020299

Nchanji E.B., Bellwood-Howard I., Schareika N., Chagomoka T., Schlesinger J., Axel D., and Rüdiger G., 2017. Assessing the Sustainability of Vegetable Production Practices in Northern Ghana. International Journal of Agricultural Sustainability, 15(3), 321-337. Retrieved from https://doi.org/10.1080/14735903.2017.1312796 
Ntshangase N.L., Muroyiwa, B., and Sibanda M., 2018. Farmers' Perceptions and Factors Influencing the Adoption of No-Till Conservation Agriculture By Small-Scale Farmers in Zashuke, Kwazulu-Natal Province. Sustainability (Switzerland), 10(2). Retrieved from https://doi.org/10.3390/Su10020555

OECD., 2001. Adoption of Technologies for Sustainable Farming Systems. In Wageningen Workshop Proceedings.

Ouiminga I., 2018. Profitability in A Sustainable Agricultural Production System: an Approach by the Soil and Water Conservation. Building a Resilient and Sustainable Agriculture in Sub-Saharan Africa, (pp. 123-145). Retrieved from https://doi.org/10.1007/978-3-319-76222-7

Pacini G.C., Lazzerini G., and Vazzana C., 2011. AESIS: A Support Tool for The Evaluation Of Sustainability Of Agroecosystems. Example of Applications to Organic and Integrated Farming Systems in Tuscany, Italy. Italian Journal of Agronomy, 6(1), 11-18. Retrieved from https://doi.org/10.4081/Ija.2011.E3

Pham L. Van, and Smith C., 2014. Drivers of Agricultural Sustainability in Developing Countries: A Review. Environment Systems and Decisions, 34(2), 326-341. Retrieved from https://doi.org/10.1007/S10669-014-9494-5

Pretty J., Toulmin C., and Williams S., 2011. Sustainable Intensification in African Agriculture. International Journal of Agricultural Sustainability, 9(1), 5-24. Retrieved from https://doi.org/10.3763/Ijas.2010.0583

Reed M.S., Fraser E.D.G., and Dougill A.J., 2006. An Adaptive Learning Process for Developing and Applying Sustainability Indicators with Local Communities. Ecological Economics, 59(4), 406-418. Retrieved from https://doi.org/10.1016/J.Ecolecon.2005.11.008

Rigby D., Woodhouse P., Young T., and Burton M., 2001. Constructing a Farm Level Indicator of Sustainable Agricultural Practice. Ecological Economics, 39(3), 463478. Retrieved from https://doi.org/10.1016/S0921-8009(01)00245-2

Riley J., 2001. The Indicator Explosion: Local Needs and International Challenges. Agriculture, Ecosystems and Environment, 87(2), 119-120. Retrieved from https://doi.org/10.1016/S0167-8809(01)00271-7

Roy R., and Chan, N.W., 2012. An Assessment of Agricultural Sustainability Indicators In Bangladesh: Review And Synthesis. Environmentalist, 32(1), 99-110. Retrieved from https://doi.org/10.1007/S10669-011-9364-3

Ruiz-Martinez I., Marraccini E., Debolini M., and Bonari E., 2015. Indicators of Agricultural Intensity and Intensification: A Review of the Literature. Italian Journal of Agronomy, 10(2), 74-84.

Retrieved from https://doi.org/10.4081/Ija.2015.656

Ryan M., Hennessy T., Buckley C., Dillon E.J., Donnellan T., Hanrahan K., and Moran B., 2016. Developing Farm-Level Sustainability Indicators for Ireland Using the Teagasc National Farm Survey. Irish Journal of Agricultural and Food Research, 55(2), 112-125. Retrieved from https://doi.org/10.1515/Ijafr-2016-0011

Sabiha N.E., Salim R., Rahman S., and Rola-Rubzen M.F., 2016. Measuring Environmental Sustainability in Agriculture: A Composite Environmental Impact Index Approach. Journal of Environmental Management, 166, 84-93. Retrieved from https://doi.org/10.1016/J.Jenvman.2015.10.003

Sánchez J.A., Reca J., and Martínez J., 2015. Water Productivity in a Mediterranean Semi-Arid Greenhouse District. Water Resources Management, 29(14), 53955411. Retrieved from https://doi.org/10.1007/S11269-015-1125-5

Santiago-Brown I., Metcalfe A., Jerram C., and Collins C., 2015. Sustainability Assessment in Wine-Grape Growing In The New World: Economic, 
Environmental, And Social Indicators for Agricultural Businesses. Sustainability, 7(7), 8178-8204. Retrieved from https://doi.org/10.3390/Su7078178

Sauvenier, Valckx X., Van Cauwenbergh J., Wauters N., Bachev E., Biala H., Bielders K., Brouckaert C., Garcia-Cidad V., Goyens V., Hermy S., Mathijs M., Muys E., Vanclooster B., Peeters M., and Alain, 2006. Framework for Assessing Sustainability Levels In Belgium Agricultural Systems - SAFE (Issue 99616). Retrieved from https://Mpra.Ub.Uni-Muenchen.De/99616/

Soldi, A., Meza, M. J. A., Guareschi, M., Donati, M., \& Ortiz, A. I. (2019). Sustainability Assessment Of Agricultural Systems In Paraguay: A Comparative Study Using FAO's SAFA Framework. Sustainability, 11(13). Retrieved from https://Doi.Org/10.3390/Su11133745

Stockle, C. O., Papendick, R. I., Saxton, K. E., Campbell, G. S., \& Van Evert, F. K. (1994). A Framework for Evaluating the Sustainability of Agricultural Production Systems. American Journal of Alternative Agriculture, 9(1-2), 45-50. Retrieved from https://Doi.Org/10.1017/S0889189300005555

Stylianou A., Sdrali D., and Apostolopoulos C.D., 2020. Integrated Sustainability Assessment of Divergent Mediterranean Farming Systems: Cyprus as a Case Study. Sustainability (Switzerland), 12(15).

Retrieved from https://doi.org/10.3390/Su12156105

Sulewski P., Kłoczko-Gajewska A., and Sroka W., 2018. Relations between AgriEnvironmental, Economic and Social Dimensions of Farms' Sustainability. Sustainability, 10(12). Retrieved from https://doi.org/10.3390/Su10124629

Talukder B., and Blay-Palmer A., 2017. Comparison of Methods to Assess Agricultural Sustainability. May 2019, 149-168. Retrieved from https://doi.org/10.1007/978-3319-58679-3_5

Taylor D.C., Mohamed Z.A., Shamsudin M.N., Mohayidin M.G., and Chiew E.F.C., 1993. Creating a Farmer Sustainability Index: A Malaysian Case Study. American Journal of Alternative Agriculture, 8(4), 175-184. Retrieved from https://doi.org/10.1017/S0889189300005403

Triviño-Tarradas P., Carranza-Cañadas P., Mesas-Carrascosa F.J., and Gonzalez-Sanchez E.J., 2020. Evaluation of Agricultural Sustainability on a Mixed Vineyard and Olive-Grove Farm in Southern Spain Through The INSPIA Model. Sustainability, 12(3). Retrieved from https://doi.org/10.3390/Su12031090

Triviño-Tarradas P., Gomez-Ariza M.R., Basch G., and Gonzalez-Sanchez E.J., 2019. Sustainability Assessment of Annual and Permanent Crops: The INSPIA Model. Sustainability (Switzerland), 11(3), 1-21. Retrieved from https://doi.org/10.3390/Su11030738

Tsymbarovich P., Kust G., Kumani M., Golosov V., and Andreeva O., 2020. Soil Erosion: an Important Indicator for the Assessment of Land Degradation Neutrality in Russia. International Soil and Water Conservation Research, 8(4), 418-429. Retrieved from https://doi.org/10.1016/J.Iswcr.2020.06.002

Tzouramani I., Mantziaris S., and Karanikolas P., 2020. Assessing Sustainability Performance at the Farm Level: Examples from Greek Agricultural Systems. Sustainability, 12(7), 14-18. Retrieved from https://doi.org/10.3390/Su12072929

United Nations Department of Economic and Social Affairs. World Population Projection; United Nations Department of Economic and Social Affairs: New York, NY, USA, 2019.

Uthes S., Kelly E., and König H.J., 2020. Farm-Level Indicators for Crop and Landscape Diversity Derived from Agricultural Beneficiaries Data. Ecological Indicators, 108(July 2019), 105725.

Retrieved from https://doi.org/10.1016/J.Ecolind.2019.105725 
Van Der Werf H.M.G., and Petit J., 2002. Evaluation of the Environmental Impact of Agriculture at the Farm Level: A Comparison and Analysis of 12 Indicator-Based Methods. Agriculture, Ecosystems and Environment, 93(1-3), 131-145. Retrieved from https://doi.org/10.1016/S0167-8809(01)00354-1

Veveris A., Šapolaite V., Raišiene A.G., and Bilan Y., 2019. How Rural Development Programmes Serve for Viability of Small Farms? Case of Latvia and Lithuania. Agris On-Line Papers in Economics and Informatics, 11(2), 103-113. Retrieved from https://doi.org/10.7160/AOL.2019.110210

Volkov A., Balezentis T., Morkunas M., and Streimikiene D., 2019. Who Benefits from CAP? The Way the Direct Payments System Impacts Socioeconomic Sustainability of Small Farms. Sustainability (Switzerland), 11(7). Retrieved from https://doi.org/10.3390/SU1 1072112

Wirén-Lehr, S. Von., 2001. Sustainability In Agriculture - An Evaluation of Principal Goal- Oriented Concepts to Close the Gap. Agriculture, Ecosystems \& Environment, 84, 115-129.

World Bank. (2008). Sustainable Land Management Sourcebook. In The International Bank for Reconstruction and Development. The World Bank. Retrieved from https://doi.org/10.1596/978-0-8213-7432-0

Zulfiqar F., and Thapa G.B., 2017. Land Use Policy Agricultural Sustainability Assessment at Provincial Level in Pakistan. Land Use Policy, 68 (February 2016), 492-502. Retrieved from https://doi.org/10.1016/J.Landusepol.2017.08.016 